OPEN ACCESS

Edited by:

Stephen Fairclough,

Liverpool John Moores University,

United Kingdom

Reviewed by:

Wei-Peng Teo,

National Institute of Education, Nanyang Technological University,

Singapore

Kazuyuki Nakagome,

National Center of Neurology and

Psychiatry, Japan

*Correspondence:

Kimberly Milla

kimmc@udel.edu

Received: 12 October 2018 Accepted: 25 April 2019

Published: 10 May 2019

Citation:

Milla K, Bakhshipour E, Bodt B and Getchell N (2019) Does Movement Matter? Prefrontal Cortex Activity During $2 D$ vs. $3 D$

Performance of the Tower of Hanol

Puzzle.

Front. Hum. Neurosci. 13:156. doi: 10.3389/fnhum.2019.00156

\section{Does Movement Matter? Prefrontal Cortex Activity During 2D vs. 3D Performance of the Tower of Hanoi Puzzle}

\author{
Kimberly Milla ${ }^{1,2 *}$, Elham Bakhshipour ${ }^{1,2}$, Barry Bodt ${ }^{3}$ and Nancy Getchell ${ }^{1,2}$ \\ ${ }^{1}$ Biomechanics and Movement Sciences Interdisciplinary Program, University of Delaware, Newark, DE, United States, \\ ${ }^{2}$ Developmental Motor Control Laboratory, Department of Kinesiology and Applied Physiology, University of Delaware, \\ Newark, DE, United States, ${ }^{3}$ Biostatistics Core, College of Health Sciences, University of Delaware, Newark, DE, \\ United States
}

In the current study, we used functional near-infrared spectroscopy (fNIRS) to compare prefrontal cortex (PFC) activity in adults as they performed two conditions of the Tower of Hanoi $(\mathrm{ToH})$ disk-transfer task that have equivalent executive function (EF) but different motor requirements. This study explored cognitive workload, here defined as the cognitive effort utilized while problem-solving by performance output. The first condition included a two-dimensional (2D) computerized ToH where participants completed trials using a computer mouse. In contrast, our second condition used a traditional, threedimensional (3D) $\mathrm{ToH}$ that must be manually manipulated. Our aim was to better understand the role of the PFC in these two conditions to detect if PFC activity increases as a function of motor planning. Twenty right-handed, neurotypical adults (10M/10F, $\bar{x}=24.6, S D \pm 2.8$ years old) participated in two blocks (one per condition) of three 1 -min trials where they were asked to solve as many puzzles as possible. These data were analyzed using a mixed effects ANOVA with participants nested within blocks for 2D vs. 3D conditions, presentation order (leading block), individual participants, and regions and additional follow-up statistics. Results showed that changes in oxygenated hemoglobin, $\Delta \mathrm{HbO}$, were significantly higher for 3D compared to 2D condition $(p=0.0211)$. Presentation order and condition interacted significantly $(p=0.0015)$. Notably, a strong correlation between performance and $\Delta \mathrm{HbO}$ existed between blocks 1 and $2(r=-0.69$, $r^{2}=0.473, p<0.01$ ) when the $3 \mathrm{D}$ condition was initially performed, in contrast to the $2 \mathrm{D}$ condition where no significant correlation was seen. Findings also showed a significant decrease in $\Delta \mathrm{HbO}$ between the first and second block $(p=0.0015)$ while performance increased significantly for both $3 \mathrm{D}$ and $2 \mathrm{D}$ conditions $(p<0.005)$. We plan to use this information in the future to narrow the potential points of impairment on the perceptioncognition-action continuum in certain developmental disabilities.

Keywords: executive function, Tower of Hanoi, fNIRS, motor learning, motor planning 


\section{INTRODUCTION}

The prefrontal cortex (PFC) is a brain structure with a significant function in planning complex cognitive behavior, personality expression, decision making, and moderating social behavior (Yang and Raine, 2009). Processes underlying high-level executive function $(\mathrm{EF})$ have historically been associated with the PFC (Ball et al., 2011). Furthermore researchers have identified neural networks that are active during complex executive processes and are highly interconnected between the PFC and several brain regions, such as the posterior parietal cortex, limbic, and cortical areas (Selemon and Goldman-Rakic, 1988; Öngür and Price, 2000; Halgren et al., 2002; Honey et al., 2002; Schall et al., 2003; Periáñez et al., 2004; Owen et al., 2005; Simmonds et al., 2008). EF is an umbrella term encompassing the higherlevel cognitive processes responsible for the completion of a specific goal and its related behaviors such as anticipation, goal establishment, monitoring of results, inhibition of action, and planning (Stuss, 1986; Moriguchi and Hiraki, 2013).

The role of the PFC in motor planning is to outline the execution of programmed sequences of actions and to plan the consequences of such actions, also referred to as internal modeling (Kawato, 1999). Specifically, the PFC is concerned with the active representation of future events resulting from behavioral actions within a framework of problem-solving, with the dorsolateral PFC particularly suited to assist in the control of responses to environmental stimuli and regulation of behavior (Wood and Grafman, 2003; Mushiake et al., 2009).

The experimental evidence for a better understanding of $\mathrm{EF}$ is the result of using different tasks such as the Stroop Task, where the ink of a word representing a color might mismatch such color (Smith et al., 2006), the Wisconsin Card Sorting Task, where participants classify cards based on different criteria (Koch et al., 2018), and the Tower of Hanoi puzzle (ToH), a disk-transfer task that requires the relocation of disks from an initial configuration to a target configuration in the least possible number of moves (Liang et al., 2016b). ToH requires participants to appropriately respond to new situations, as well as demands related to anticipatory, means-end problemsolving (Welsh and Huizinga, 2001). Moreover, it has been used for decades as a neuropsychological task for assessing EF on healthy individuals and different clinical populations (Goel and Grafman, 1995; Slomine et al., 2002; Griebling et al., 2010; Yu et al., 2016; Shuai et al., 2017). Previous research utilizing Tower tests have all resulted in PFC activity, including the anterior, inferior, and dorsolateral regions, despite the use of different parameters (i.e., the amount, size, and color of the disks used; Baker et al., 1996; Boghi et al., 2006; Wagner et al., 2006; Just et al., 2007; den Braber et al., 2008; Fitzgerald et al., 2008; Campbell et al., 2009; Zhu et al., 2010; Kaller et al., 2011; Stokes et al., 2011; de Ruiter et al., 2009; Hahn et al., 2012; Ruocco et al., 2014). Furthermore, an increase in the difficulty of the task (i.e., increased number of moves necessary to reach the target state) led to increased levels of activity, particularly in the left dorsolateral region of the PFC (dlPFC). The left dlPFC has been related to the identification of information relevant to the goal and creation of an internal problem representation, whereas the right dlPFC has been associated with mental transformations and working memory (Ruocco et al., 2014).

Notably, the ToH puzzle has the advantage of being sensitive to disruption in the PFC (Simon, 1975; Saint-Cyr et al., 1988; Casey et al., 1994; Goel and Grafman, 1995). Additionally, the activity of the PFC during the computerized version of $\mathrm{ToH}$ has been shown using different neuroimaging techniques such as fMRI (Head et al., 2002; Griebling et al., 2010; Crescentini et al., 2012) and EEG (Ruiz-Díaz et al., 2012; Guevara et al., 2013), in addition to functional near-infrared spectroscopy (fNIRS; Liang et al., 2016a,b). fNIRS is a neuroimaging tool that is non-invasive, portable, affordable, and safe for continuous and repeated measurements. fNIRS indirectly measures neural activity using the neurovascular coupling principle (i.e., blood flow follows neural activity). This phenomenon occurs when increases in neural activity also increase the delivery of oxygen and glucose for consumption, leading to closely associated increases in blood flow. Ultimately, the increased blood flow into the capillary beds facilitates access to oxygenated hemoglobin in the local tissue. Thus, neurovascular coupling results in a hemodynamic response that reflects the location and magnitude of neural activity, which allows us to use oxy$(\Delta \mathrm{HbO})$ and deoxy-Hb $(\Delta \mathrm{HbR})$ as markers for brain activity (Kim et al., 2017).

Along with its tolerance to motion, assuming movement of the head is limited (Izzetoglu et al., 2005), strong correlation with fMRI in measurements of hemodynamic responses (Kleinschmidt et al., 1996; Ferrari and Quaresima, 2012), better spatial resolution than MEG and EEG as well as better temporal resolution than fMRI and PET (Bunce et al., 2006; Irani et al., 2007), fNIRS is ideal to study cognitive activity during behavioral tasks in ecologically relevant conditions (Kim et al., 2017), including in children (Caçola et al., 2018). Therefore, it is appropriate for investigating different conditions of the $\mathrm{ToH}$ including both three-dimensional (3D) and two-dimensional (2D) modalities.

Our specific aim was to determine if PFC hemodynamics and behavioral performance differ as a function of ToH condition (3D vs. $2 \mathrm{D}$ ) in neurotypical young adults. We hypothesized that there would be greater changes in $\Delta \mathrm{HbO}$ during the $3 \mathrm{D}$ condition as compared to the $2 \mathrm{D}$ condition of the ToH task (H1). Additionally, we hypothesized that each condition would show regional areas with greater changes in oxygenation than other regions within the same condition $(\mathrm{H} 2)$.

\section{MATERIALS AND METHODS}

\section{Participants}

Twenty-seven neurotypical adults aged between 18 and 35 were initially recruited for this study from the University of Delaware and Newark communities. Participants were included if they were healthy, right handed, and without known neurological deficits. Three participants were not included due to being lefthanded. Exclusion criteria included any head injury within the 6 months prior to testing, an open wound on the forehead, or a seizure disorder. After data collection, an additional 
three participants were excluded due to incomplete data sets and one participant was excluded due to being an outlier, i.e., hemodynamic data was over two standard deviations from the mean, leaving a total of $n=20$ neurotypical adults $(10 \mathrm{~F} / 10 \mathrm{M})$ with a mean age of $24.6(\mathrm{SD} \pm 2.8)$ years old. To ensure that participants were right hand dominant, they completed the Edinburgh Handedness Inventory to assess hand preference for various tasks, such as writing (Oldfield, 1971). Participants were all right-handed and had a mean Laterality Quotient (L.Q.) of 79.2 (SD \pm 19.6$)$ with an average Decile of 5.4 (SD \pm 3.3; Oldfield, 1971). Sixteen participants had no previous experience solving the $\mathrm{ToH}$ puzzle, i.e were task naïve, and the remaining four were self-described beginners, meaning they have had minimal experience solving the $\mathrm{ToH}$ puzzle. Participants averaged $172( \pm 9.61) \mathrm{cm}$ in height and $73.91( \pm 14.77) \mathrm{kg}$ in body mass. The Institutional Review Board at the University of Delaware approved the protocol for this study and participants provided written informed consent after being educated on the study and its procedures.

\section{Experimental Design}

\section{Conditions}

The present study used two conditions: a 3D and a 2D modality of the ToH task. The first condition involved the use of a 3D wooden model, with three peg-holes and four graduated disks, which was physically manipulated during puzzle solving (Figure 1A). The second condition involved the use of a $2 \mathrm{D}$ computer model with custom-made opensource software (Salesforce Company, 2018), also consisting of three peg-holes and four graduated disks however manipulated through a computer mouse by clicking and dragging (Figure 1B). Block order (B1/B2) was randomized and counterbalanced using an online randomized integer sequence calculator (Haahr, 1998) resulting in eight participants initially performing the $3 \mathrm{D}$ condition $(3 \mathrm{D} / \mathrm{B} 1)$ and 12 participants initially performing the $2 \mathrm{D}$ condition $(2 \mathrm{D} / \mathrm{B} 1)$.

\section{Protocol}

Participants became familiar with the ToH puzzle by performing a practice attempt for each condition using three disks; there were no time constraints for this practice. Following practice, participants had a 1-min rest period, in which they comfortably sat on a chair and focused their attention on a green cross on a screen in front of them, with their eyes open and sitting as still as possible. Following the initial rest period, participants attempted to solve $\mathrm{ToH}$ puzzles in two blocks (one per condition; block $1=\mathrm{B} 1$ and block $2=\mathrm{B} 2$ ), each consisting of three 1-min epochs with a 20 -s rest in between to allow hemodynamic flow to return to baseline (Kuhtz-Buschbeck et al., 2003; Abibullaev et al., 2014; Yin et al., 2015; Huhn et al., 2019; Table 1). Using Welsh and Huizinga's (2001) ToH-Revised list containing 22 items, 10 different puzzle configurations were created. Each puzzle had a unique combination of start and end disk positions, which in turn were ordered into two different sequences to avoid an order effect. Puzzles varied in difficulty, with the minimum number of moves required to solve a puzzle ranging from 8 to 15 (Supplementary Figures S1-S3 show the two sequences of 10 puzzles used in this study with associated difficulty). Furthermore, puzzle sequence was randomized and counterbalanced. Each participant was presented with the same puzzle sequence for both $3 \mathrm{D}$ and $2 \mathrm{D}$ conditions, i.e., they were presented with different puzzles in each sequence but the sequence was identical for both blocks, allowing for a second attempt at a given puzzle if the previous puzzle was solved. After each block, participants had a 1-min rest period.

\section{Experimental Device}

A 16-channel continuous-wave functional near-infrared (fNIRS) device (Ayaz et al., 2012, 2013) was utilized to collect data from the PFC of all participants (fNIR Devices LLC, Potomac, MD, USA). The sensor included 10 photo detectors and four light emitters (16 optodes total), each releasing light at 730-850 nm wavelengths and separated by $2.5 \mathrm{~cm}$, which allowed for a penetration depth of about $1.2 \mathrm{~cm}$ (Ayaz et al., 2011).

The fNIRS sensor band was placed on top of the participants' forehead such that the center of the sensor's horizontal axis was aligned to the center of the participants' head (symmetry axis of the head). The sensor's vertical axis was positioned in the Fp1 and Fp2 locations in accordance to the international 10-20 system of cerebral electrode placement (Homan et al., 1987; Ayaz et al., 2006). Figure 2 depicts the fNIRS sensor band
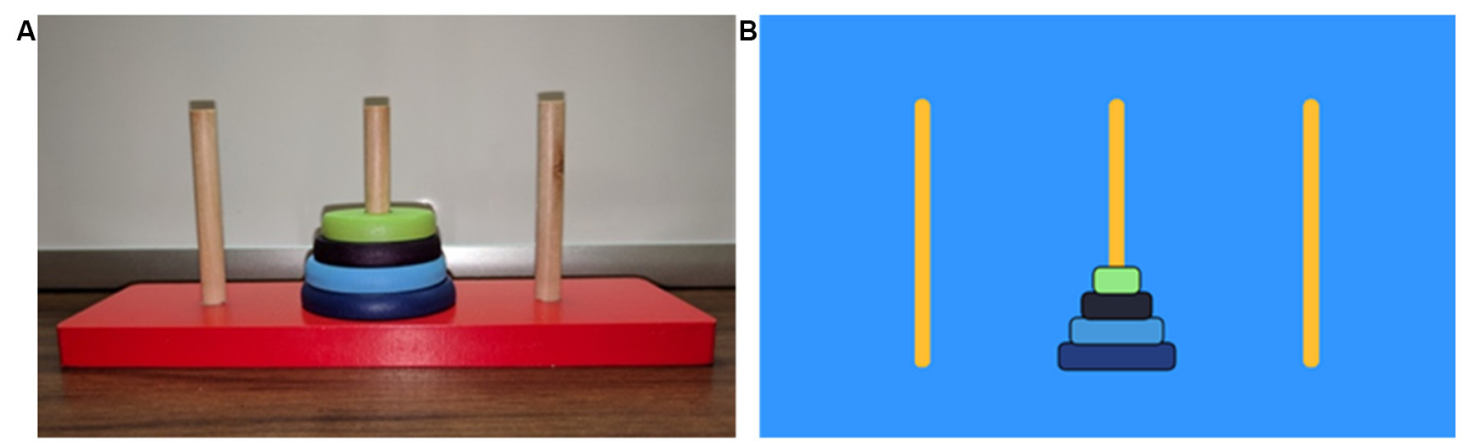

FIGURE 1 | Different Tower of Hanoi (ToH) conditions. (A) Three-dimensional (3D) condition performed by using one hand to move disks and the other hand to hold the frame. (B) Two-dimensional (2D) condition performed on a PC computer using one hand to manipulate a mouse. 
TABLE 1 | Protocol timeline for 3D/B1 participants.

\begin{tabular}{|c|c|c|c|c|c|c|c|c|c|c|c|c|c|c|}
\hline Practice & & Rest & & & & & & Rest & & & Block 2 & & & Rest \\
\hline $3 D$ & $2 \mathrm{D}$ & $\mathrm{R}$ & $3 D-1$ & $\mathrm{R}$ & $3 D-2$ & $\mathrm{R}$ & $3 D-3$ & $\mathrm{R}$ & $2 \mathrm{D}-1$ & $\mathrm{R}$ & $2 \mathrm{D}-2$ & $\mathrm{R}$ & $2 \mathrm{D}-3$ & $\mathrm{R}$ \\
\hline- & - & $60 \mathrm{~s}$ & $60 \mathrm{~s}$ & $20 \mathrm{~s}$ & $60 \mathrm{~s}$ & $20 \mathrm{~s}$ & $60 \mathrm{~s}$ & $60 \mathrm{~s}$ & $60 \mathrm{~s}$ & $20 \mathrm{~s}$ & $60 \mathrm{~s}$ & $20 \mathrm{~s}$ & $60 \mathrm{~s}$ & $60 \mathrm{~s}$ \\
\hline
\end{tabular}

Participants were introduced to the puzzle with a practice attempt for each condition, followed by a 1-min rest period prior to completing two blocks of problem-solving. 3D, threedimensional ToH condition; 2D, two-dimensional ToH condition; $R$, rest.

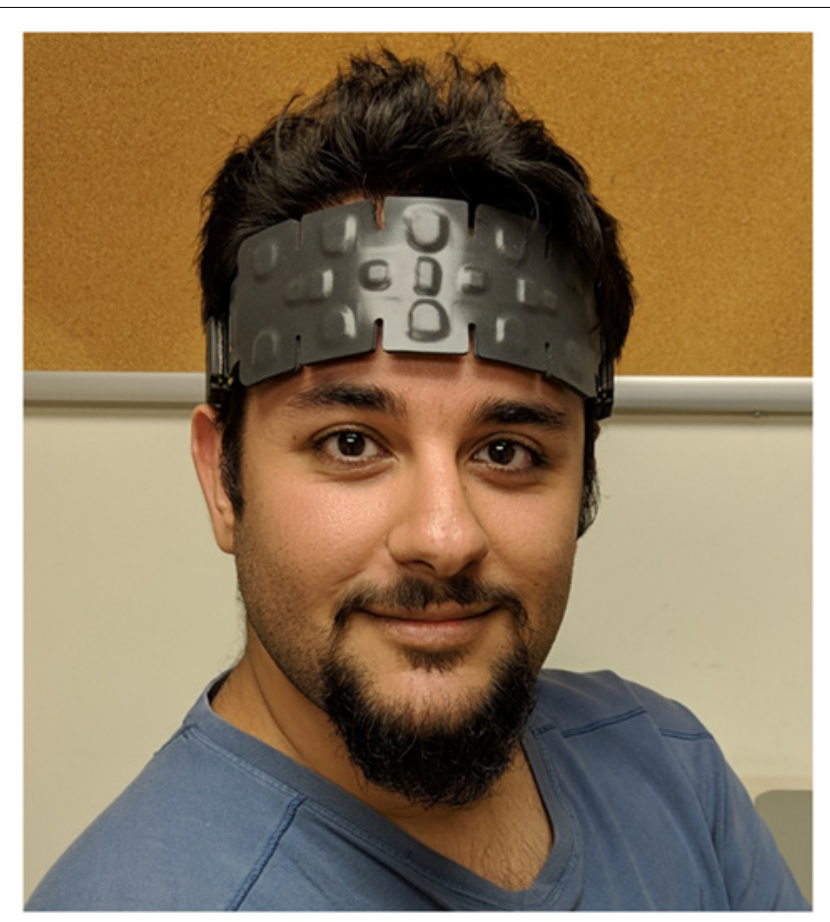

FIGURE 2 | $\mathrm{fNIR}{ }^{\circledR}$ sensor pad used for data collection. Written informed consent was obtained from the individual to publish this image.

used in this study (fNIR Devices LLC, Potomac, MD, USA) and Figure 3 shows an fMRI-based topographic map of the brain (Ayaz et al., 2018).

\section{Data Acquisition and Analysis}

fNIRS data were sampled at $2 \mathrm{~Hz}$ and acquired using Cognitive Optical Brain Imaging (COBI) studio software (Ayaz et al., 2011). Data were processed using fNIRSoft Software (Version 4.9, Ayaz et al., 2018) and represents the mean activation during all three 1-min blocks for each condition. The device was initiated and the first $10 \mathrm{~s}$ were utilized as baseline prior to task initiation. During this time, the participant remained still and focused on a green cross located in a computer screen across from the participant. Before placing the sensor band, an alcohol swab was used to clean the forehead of the participants and the light in the testing room was subsequently reduced. Researchers were careful to exclude any hair between the sensors and the participants' forehead to obtain optimal signal acquisition.

Raw light intensities were visually inspected and individual optodes rejected when data did not reflect hemodynamic activity due to lack of proper contact between the sensors and the forehead or placement on top of hair. Researchers also visually inspected the data and manually removed optodes in accordance to Ayaz et al. (2011). Then, a finite impulse response (FIR) filter (20th order, Hamming window) was used to low-pass filter the raw light intensity data at $0.1 \mathrm{~Hz}$ to remove input from physiological signals, such as respiration and heartbeat. Data were subsequently converted to changes in concentration using the modified Beer-Lambert law (Cope and Delpy, 1988) and depicted into four outcome measures: change in oxygenated hemoglobin $(\Delta \mathrm{HbO})$, change in deoxygenated hemoglobin $(\Delta \mathrm{HbR})$, total change in hemoglobin $(\Delta \mathrm{HbT})$ and total change in oxygenation $(\Delta \mathrm{Oxy})$. We restricted our analysis to $\Delta \mathrm{HbO}$ because our preliminary analysis showed high correlation among $\Delta \mathrm{HbO}, \Delta \mathrm{HbT}$, and $\Delta \mathrm{Oxy}$, in addition to $\Delta \mathrm{HbO}$ having stronger and more wide-spread signals than those from $\Delta \mathrm{HbR}$ and $\Delta \mathrm{HbT}$ (Zhang et al., 2011), including in the ToH task (Liang et al., 2016a,b). Furthermore, it has been shown that $\triangle \mathrm{HbO}$ has a strong correlation to BOLD signal whereas $\triangle \mathrm{HbR}$ has a weak correlation (Strangman et al., 2002), in addition to better signal-to-noise ratio (SNR) than $\Delta \mathrm{HbR}$ (Hoshi, 2007; Zhang et al., 2010). Finally, data depicting changes in concentration were processed using the detrending filter, which removes a drift in the data using linear parameters that convert the slope of the baseline to zero.

Hemodynamic data for 20 participants were included in the analyses and reflected a mean activation of the three 1-min epochs for each condition. Furthermore, performance data for 17 participants were included in the analyses, defined as the number of puzzles a participant attempted to solve within each block out of 10 potential puzzles. Due to data collection error, performance data were not obtained for three participants.

\section{Statistical Analysis}

Data were analyzed in JMP ${ }^{\circledR}$ Pro 13.1.0. The effects of $2 \mathrm{D}$ vs. $3 \mathrm{D}$ conditions, presentation order (leading block), individual participants, and regions were examined using a mixed effects ANOVA with participants nested within blocks. A separate analysis was conducted for each of four representations of the optodes based on the sensor layout (Figures 3B-D). Those four representations depicted data for the complete PFC (overall), a division of the PFC into four regions (left lateral, left medial, right medial, and right lateral), a division of the PFC into eight regions (left lateral dorsal and ventral, left medial dorsal and ventral, right medial dorsal and ventral, and right lateral dorsal and ventral), and a division of the PFC into 16 regions, i.e., data for each of the individual optodes. An exploratory analysis subsequent to ANOVA investigated the significance of conditions by considering paired differences between $2 \mathrm{D}$ and $3 \mathrm{D}$ for each participant and each optode 


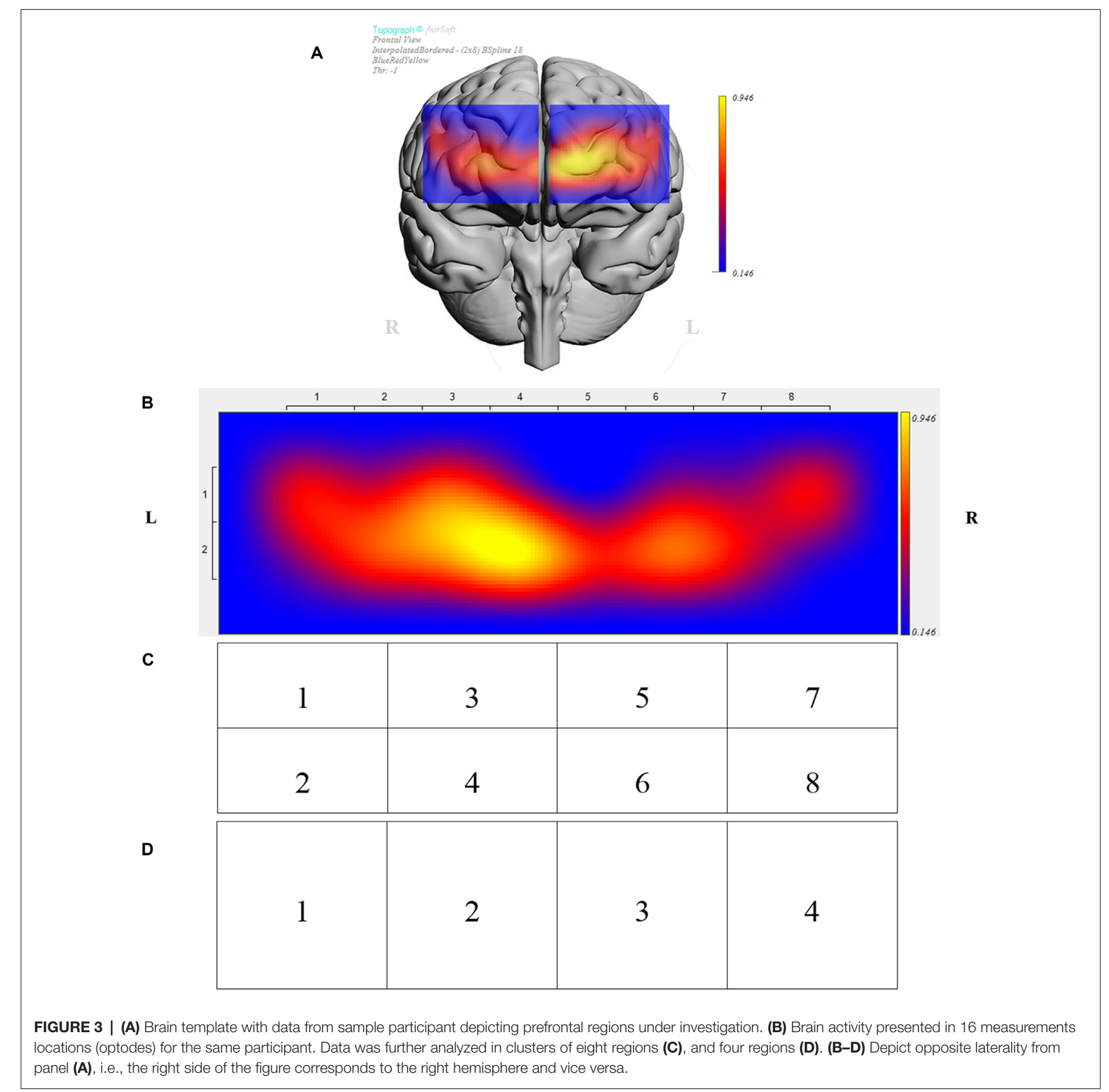

representation in Tukey mean difference plots. A regression analysis showed the association between performance (puzzles attempted) and $\Delta \mathrm{HbO}$.

\section{RESULTS}

\section{$\Delta \mathrm{HbO}$ in 2D vs. 3D Conditions}

A mixed-effects ANOVA based on a mean $\triangle \mathrm{HbO}$ response over all optodes was performed with conditions, presentation order, participants within blocks, and region as factors. As predicted, overall $\Delta \mathrm{HbO}$ was significantly higher for the $3 \mathrm{D}$ condition compared to the $2 \mathrm{D}$ (Figure $4, p=0.0211$ ). In addition, a significant interaction existed between the order of presentation and condition (Figure 5, $p=0.0015$ ), with those participants who started with $3 \mathrm{D}$ in block 1 (3D/B1) showing a much larger change in $\Delta \mathrm{HbO}$ than those who started with 2D (2D/B1). Additionally, participant responses to experimental conditions were not universal: there were significant interactions between condition and participant $(p=0.0013)$, region and participant $(p=0.0124)$, and there was a three-way interaction of participant $\times$ region $\times$ block order $(p<0.0001)$. 


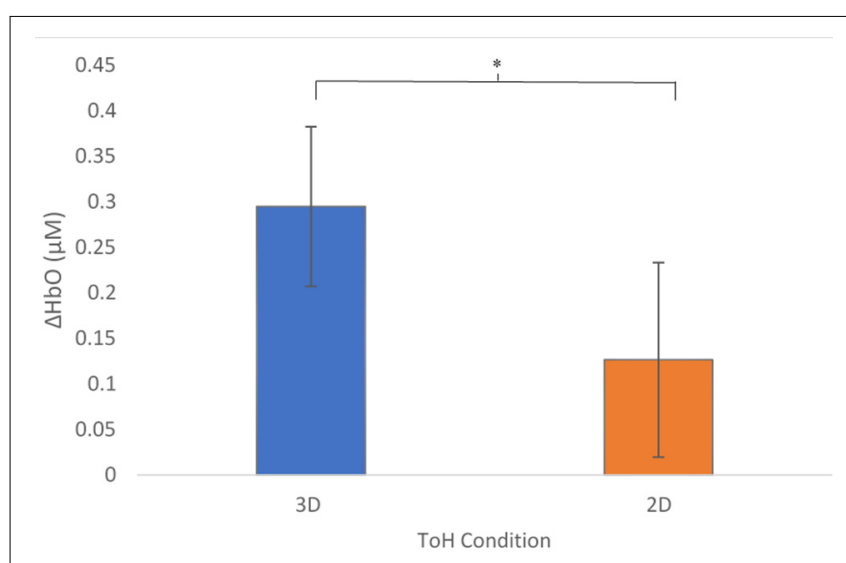

FIGURE 4 | Mean Changes in oxygenated hemoglobin, $\Delta \mathrm{HbO}(\mu \mathrm{M})$ as a function of condition. The 3D condition showed significantly higher activity, $p=0.0207$. Error bars show standard error values. ${ }^{*}$ denotes statistical significance.

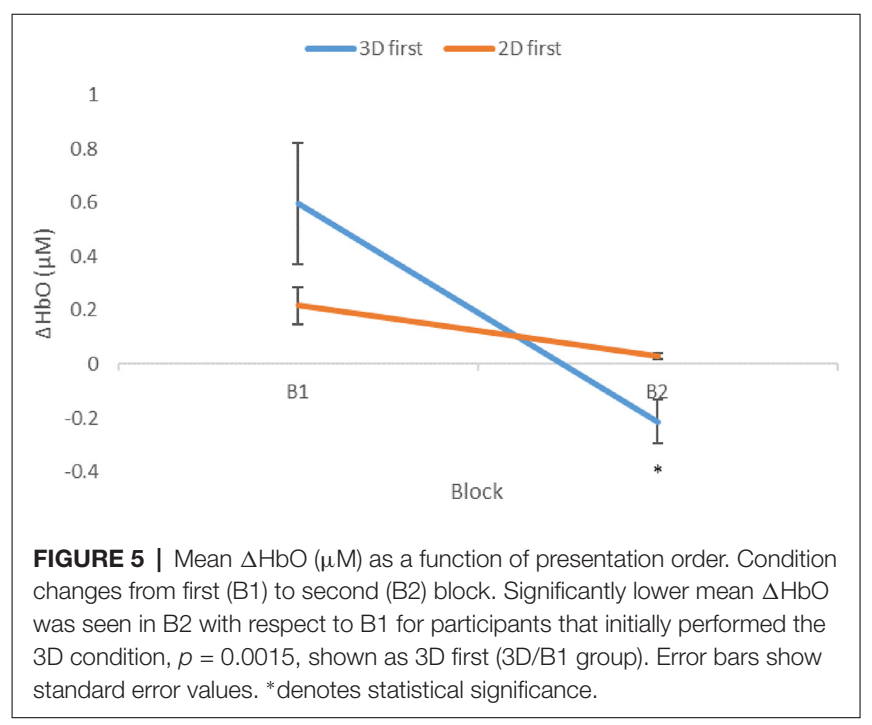

\section{$\Delta \mathrm{HbO}$ and Regional Analysis}

With a similar mixed-effect ANOVA analysis using individual optode recordings for $\triangle \mathrm{HbO}$, no significant differences were seen in regional activity using the 16,8 , or 4 optode model with this particular group $(p>0.05)$. In other words, specific sets of optodes did not show higher $\Delta \mathrm{HbO}$ activity within a condition.

\section{$\Delta \mathrm{HbO}$ and Performance on $\mathrm{ToH}$}

$\Delta \mathrm{HbO}$ decreased significantly between the first and second block ( $p=0.0015)$; at the same time, the total number of puzzles solved increased significantly for both $3 \mathrm{D}$ and $2 \mathrm{D}$ conditions $(\mathrm{B} 1=3.56, \mathrm{~B} 2=4.50, p<0.005)$. Furthermore, there was a negative correlation between the number of puzzles solved and $\Delta \mathrm{HbO}(r=-0.37)$, suggesting that participants learned the $\mathrm{ToH}$ task and could perform it with less cognitive effort in the second block.
Notably, when the 3D condition was performed in block 1 (3D/B1), a significant negative correlation between performance and $\Delta \mathrm{HbO}$ existed $\left(r=-0.69, r^{2}=0.473, p<0.01\right.$, Figure 6). In contrast, when participants started with the $2 \mathrm{D}$ condition, there was no significant correlation between B1 and $\mathrm{B} 2(r=-0.177$, $\left.r^{2}=0.0313, p>0.05\right)$ when the $2 \mathrm{D}$ condition was performed in block $1(2 \mathrm{D} / \mathrm{B} 1$, Figure 6). Due to the significant interaction found between conditions (2D vs. 3D) and condition order (leading block) along with the correlation differences, we followed up with an analysis of relative neural efficiency (Paas and Van Merriënboer, 1993; Paas et al., 2003). Both groups improved relative neural efficiency from $\mathrm{B} 1$ to $\mathrm{B} 2$, but the amount of change differed substantially. The calculated relative neural efficiency for 3D/B1 participants was -5.82 for block 1 and 5.64 for block 2. In contrast, the $2 \mathrm{D} / \mathrm{B} 1$ participants had a relative neural efficiency of -1.37 for block 1 and 1.44 for block 2 (Figure 7).

\section{DISCUSSION}

\section{Changes in Oxyhemoglobin as a Function of Puzzle Type}

As we hypothesized, $\Delta \mathrm{HbO}$ was significantly higher for the $3 \mathrm{D}$ condition compared to the $2 \mathrm{D}$ condition overall (Figure 4). This suggests that the 3D condition placed higher cognitive demands on the participants in order to solve the puzzle, which may be due to greater demands on perceptual decision-making processes (object identification, selection, and localization) due to the integration of increased spatial and tactile sensory processing (Wong et al., 2015). Additionally, higher demands on motor planning, i.e., increased demands on abstract kinematics, action selection, and movement (Wong et al., 2015), would be imposed by the $3 \mathrm{D}$ condition with respect to the $2 \mathrm{D}$ condition.

Furthermore, participant responses to experimental conditions varied on the basis of condition, presentation order, and region, as demonstrated by the significant interactions (condition and participant, region and participant, participant $\times$ region $\times$ presentation order). These results provide further support for individual differences in EF (Ackerman, 1987, 1988; Miyake et al., 2000; Osaka et al., 2004; Miyake and Friedman, 2012; Smith et al., 2019) since participants had different levels and patterns of neural activity for each condition between each other (interpersonal differences) and amongst themselves (intrapersonal differences). Given that performance in the $\mathrm{ToH}$ task has been associated to inductive reasoning as well as other aspects of fluid intelligence (Welsh et al., 1999; Devine et al., 2001; Lock et al., 2002), the study done by Dunst et al. (2014) is of relevance. Brain activity between "brighter" and "less bright" participants was compared as they worked on a number-series task taken from the numerical-inductive reasoning (Arendasy and Sommer, 2012) of the intelligencestructure-battery (INSBAT, Arendasy, 2008). They found significant differences in brain activity within eight regions (particularly left inferior frontal, left middle frontal, and right middle frontal), when the task difficulty was not standardized, i.e., adjusted for each participant according to their ability based 


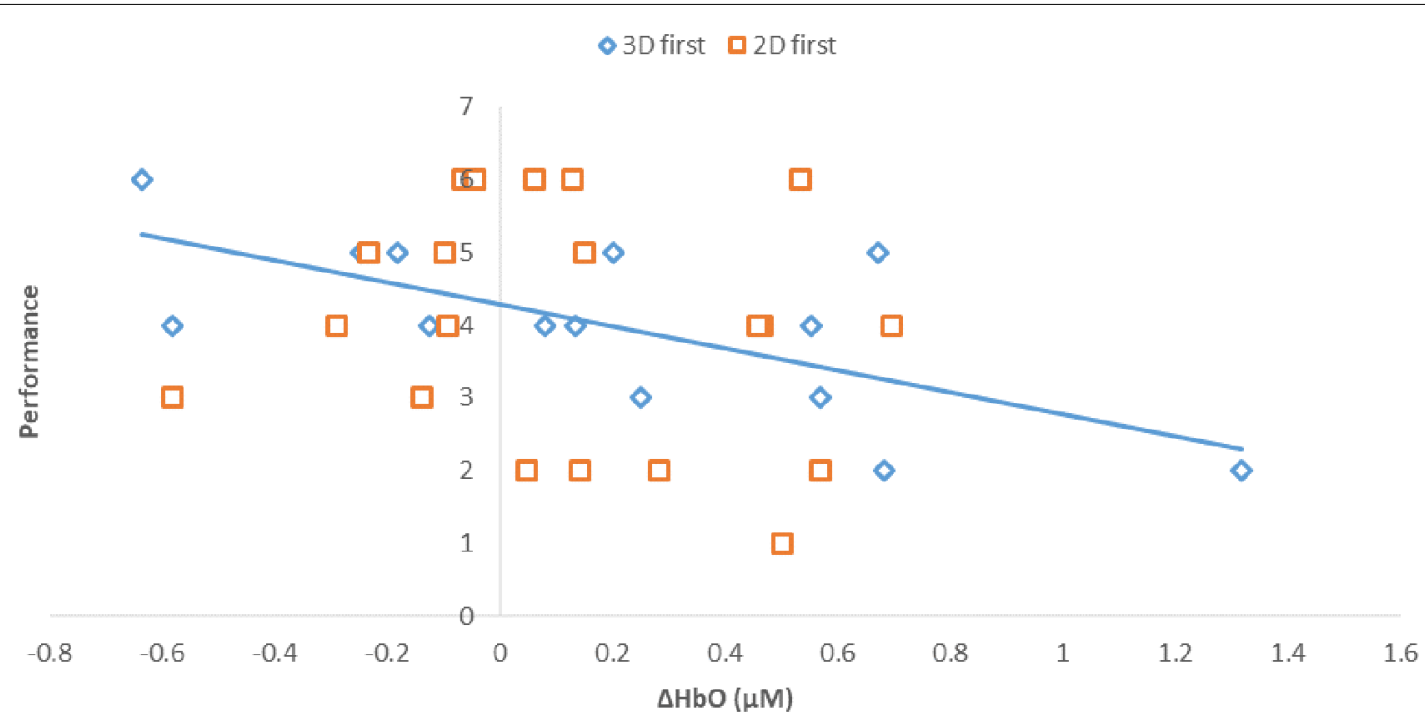

FIGURE 6 | Correlations between performance (\# of puzzles attempted to solve) and prefrontal activity ( $\Delta \mathrm{HbO}, \mu \mathrm{M})$. Regression line shows the strong correlation, $r^{2}=0.473, p<0.01$, found in participants that initially performed the 3D condition, shown as 3D first (3D/B1 group).

on intelligence scores. Our study did not standardize the ToH task difficulty based on participants' ability, thus individual differences can be partially explained by ability in terms of fluid intelligence.

Moreover, it has been suggested by Simon (1975) that the restrictions of the $\mathrm{ToH}$ task lead to the creation of various problem-solving strategies with varying effectiveness and that can account for individual differences, particularly for performance. Furthermore, Simon (1975) proposes the recursive guiding solution method as the optimal problem-solving strategy since it decreases the demands placed on working memory, planning, and inhibition (all executive processes) by the inherent complexity of the ToH puzzle. The recursive guiding solution begins with moving the largest disk to the end-goal position, followed by moving the smaller disk out of the way and in the open peg (subpyramid stack of smaller disks), and then restarting the process by moving the largest disk in the subpyramid to the end-goal position and repeating all steps until reaching the solution (Simon, 1975).

\section{Prefrontal Cortex: Overall vs. Regional Differences}

Contrary to our hypothesis and despite previous studies demonstrating that hemodynamic responses can be used to reliably quantify cognitive state and load levels in the bilateral PFC (Basso Moro et al., 2013; Fishburn et al., 2014; Unni et al., 2015; Bonetti et al., 2019), the present study did not find significant differences among optodes when parsed into different regions. Although the lack of regional differences is important, it is worthwhile to note that fNIRS' spatial resolution is limited by the optical source-detector distance, which is normally $2-3 \mathrm{~cm}$, despite the technology having high temporal resolution (Tak et al., 2016). This relatively low spatial resolution, compared to fMRI, may cause difficulties in localizing different regions of the brain. Additionally, this study analyzed regional differences based on the layout of the device ( 4,8 , and 16 regions), which may not have been appropriate to parse out the functional activity of the PFC.

Moreover, the present study did not stratify participants based on individual differences shown to reflect distinct brain activity, such as fluid intelligence and spatial ability (Lamm et al., 2001; Neubauer and Fink, 2009; Dunst et al., 2014). The presence of individual differences, as described above, might have precluded our ability to detect regional differences. Lastly, previous research has shown that restricting the processing time during a cognitive task can affect the magnitude and patterns of neural activity (Porebski, 1954; McCarthy and Wood, 1985; Van Breukelen and Roskam, 1991; Haig et al., 1997; Gulliksen, 2013), and even increase the demand for neural resources (Lamm et al., 2001). It could be that restricting the time to complete puzzles to 1-min epochs affected our study in unexpected ways. Other analysis techniques that take into consideration temporal aspects of each epoch, such as a time-series analysis, might lead to identification of differences.

\section{Associations Between Brain and Behavior}

There may have been a learning effect across the blocks, as $\Delta \mathrm{HbO}$ decreased significantly between $\mathrm{B} 1$ and $\mathrm{B} 2$ while the total number of puzzles solved increased significantly, regardless of condition order. Since prior knowledge reduces the cognitive load inherent to task complexity, also known as the intrinsic load (Kalyuga et al., 2004; Sweller, 2008), having solved the same puzzles in B1 as in B2 likely reduced this intrinsic load placed by the puzzle in B2. This shift in cognitive load from B1 to B2 led to an approximation of the "ideal" load for the task, also known as germane cognitive load, thereby reducing the amount of neural resources needed to solve the puzzle (Sweller, 2008; Taylor, 2013). This is further supported by the negative 


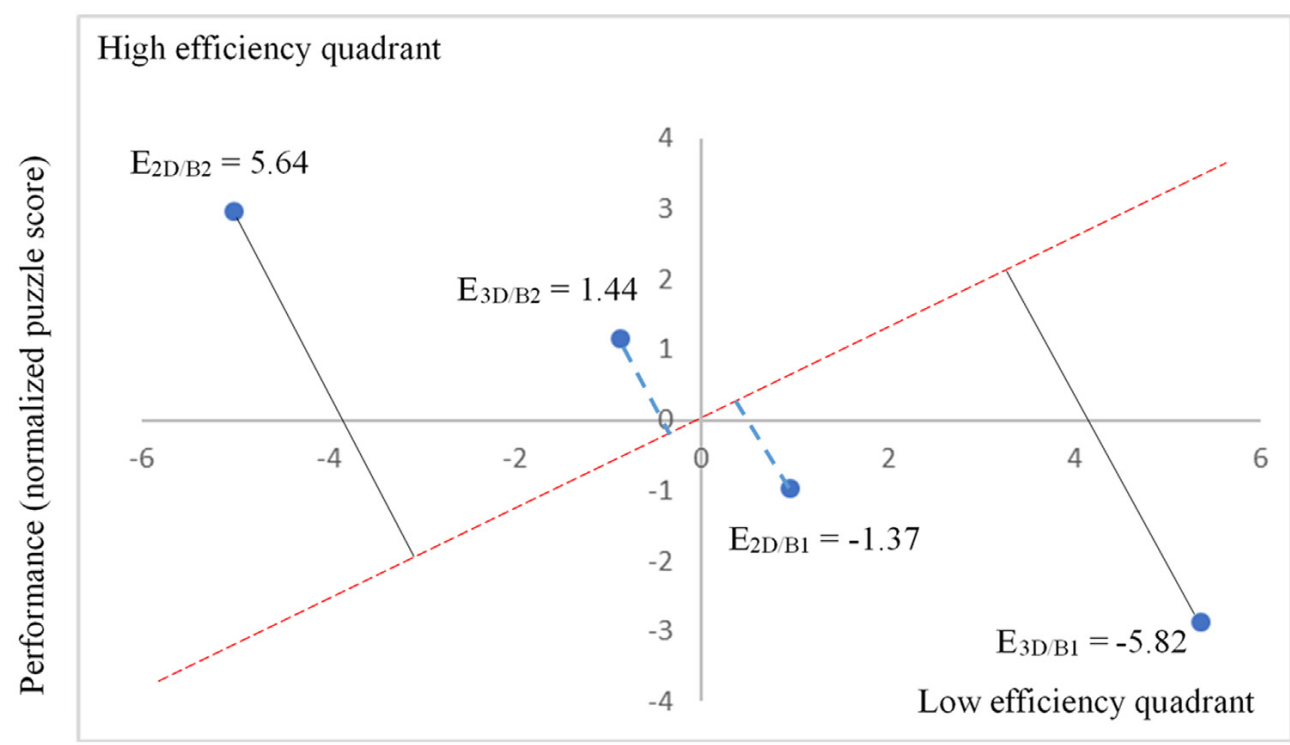

Cognitive Effort (normalized $\Delta \mathrm{HbO}, \mu \mathrm{M}$ )

FIGURE 7 | Relative neural efficiency as measured by performance (normalized puzzle score) and cognitive effort (normalized $\Delta \mathrm{HbO}, \mu \mathrm{M}$ ).

correlation seen between the number of puzzles solved and $\Delta \mathrm{HbO}$, suggesting that participants may have progressively learned to solve the ToH task and could perform it with less cognitive effort in $\mathrm{B} 2$ due to a more efficient use of neural resources.

Our results support evidence from previous studies in neural efficiency, listed in the review by Neubauer and Fink (2009), where a negative relationship between brain activation and task performance has been consistently seen on tasks of low to medium difficulty or complexity, indicating a potential association between performance and cognitive load. Likewise, our results further support previous evidence where practice has led to a significant negative correlation between performance and neural activation, indicating a more discriminating activity of neural circuitry in $\mathrm{B} 2$ due to a sharpened cognitive strategy gained during B1 (Haier et al., 1988, 1992).

As previously mentioned, presentation order (leading block) and condition interacted significantly (Figure 5 ), showing a significant negative correlation between performance and $\Delta \mathrm{HbO}$ (Figure 6) for 3D lead participants (3D/B1 group) as opposed to $2 \mathrm{D}$ lead participants (2D/B1 group). A relative neural efficiency analysis (Paas and Van Merriënboer, 1993; Paas et al., 2003) showed that while both groups improved relative neural efficiency from B1 to B2, the magnitude of change was considerably different, with those starting with the $3 \mathrm{D}$ condition showing increases in neural efficiency that were five times greater than those starting with $2 \mathrm{D}$. This suggests that learning the $\mathrm{ToH}$ using the $3 \mathrm{D}$ puzzle, while more difficult, leads to higher cognitive efficiency in subsequent trials. Because of the task design, it is unclear if this improvement in neural efficiency would occur if the participants continued to perform the task manually.
As previously mentioned, 2D/B1 participants did not show a significant correlation between B1 and B2. Since a significant negative correlation between performance and neural activity indicates a shift towards higher neural efficiency, it can be concluded that participants in the $2 \mathrm{D} / \mathrm{B} 1$ group did not learn the task, at least not as well as 3D/B1 participants. While this is an immediate effect given our study's paradigm, our results are consistent with the study by Kantak et al. (2017) where they found that practicing a complex skill improves the long-term performance of the unpracticed simpler goal-directed task. The complex task presents the participant with higher motor and/or cognitive load, which in turn increases neuroplastic changes across the cognitive-motor network, essential for learning and its transfer (Nudo et al., 1996; Plautz et al., 2000; Meehan et al., 2011; Lefebvre et al., 2015; Wadden et al., 2015).

The improvement in neural efficiency in the $3 \mathrm{D} / \mathrm{B} 1$ group may be a result of a contextual interference effect, where initial high contextual interference during skill acquisition leads to an initial decrement in performance followed by better performance once the skill is learned, as compared to a low interference task (Lee et al., 1992). In this study's paradigm, the change in performance from $\mathrm{B} 1$ to $\mathrm{B} 2$ was greater when the $3 \mathrm{D} \mathrm{ToH}$ condition was performed, along with the highest overall $\triangle \mathrm{HbO}$ and subsequent lowest overall $\Delta \mathrm{HbO}$ in the $2 \mathrm{D} \mathrm{ToH}$ condition. Thus, having a more complex modality of a task, i.e., a 3D puzzle, would place higher demands on sensory information processing in addition to motor planning demands, which can be seen as interfering with the task itself and therefore increasing cognitive load. This result is analogous to that of Welsh and Huizinga (2005) where two sets of participants were administered either a blocked schedule of increasingly difficult $\mathrm{ToH}$ puzzles, or a random schedule with randomized order 
of puzzle difficulty. They found that as expected, the blocked group had a decrease in performance, whereas the random group increased their accuracy thereby evidencing a learning effect (Welsh and Huizinga, 2005).

\section{Limitations and Future Directions}

One limitation to this study is that participants were not stratified by individual differences, particularly differences that have been shown to reflect distinct brain activity such as fluid intelligence and spatial ability (Lamm et al., 2001; Neubauer and Fink, 2009; Dunst et al., 2014). Future work can address this limitation by creating distinct groups based on relevant individual differences amongst the participants. Additionally, future work can utilize other analysis techniques that take into consideration temporal aspects of each epoch, in order to further assess for regional differences, and expand analysis by using a system that allows to visualize more regions of the brain.

\section{CONCLUSION}

To our knowledge, this is the first study that investigated the neural activity of the PFC while controlling the cognitive component and manipulating movement, using a $3 \mathrm{D}$ and $2 \mathrm{D}$ modality of the ToH puzzle. To answer the question posed by our title, it appears that, in fact, movement does matter. Our results showed higher oxyhemoglobin concentration for the $3 \mathrm{D}$ condition compared to the $2 \mathrm{D}$ condition, suggesting a higher complexity for the $3 \mathrm{D}$ condition due to increased demands on sensory processing and integration as well as motor planning. Practice and the order of presentation contributed to a learning effect, where oxyhemoglobin decreased and performance increased from B1 to B2 overall, however, the relationship was significant for the $3 \mathrm{D} / \mathrm{B} 1$ group unlike the $2 \mathrm{D} / \mathrm{B} 1$ group. This suggests that not only practice is important for performance, but also the complexity of the task first performed which in turn leads to a refined cognitive strategy as shown by the considerable decrease in oxyhemoglobin concentration from $\mathrm{B} 1$ to $\mathrm{B} 2$ in the $3 \mathrm{D} / \mathrm{B} 1$ group. Overall, our results further

\section{REFERENCES}

Abibullaev, B., An, J., Jin, S. H., and Moon, J. I. (2014). Classification of brain hemodynamic signals arising from visual action observation tasks for brain-computer interfaces: a functional near-infrared spectroscopy study. Measurement 49, 320-328. doi: 10.1016/j.measurement.2013.11.044

Ackerman, P. L. (1987). Individual differences in skill learning: an integration of psychometric and information processing perspectives. Psychol. Bull. 102, 3-27. doi: 10.1037/0033-2909.102.1.3

Ackerman, P. L. (1988). Determinants of individual differences during skill acquisition: cognitive abilities and information processing. J. Exp. Psychol. Gen. 117, 288-318. doi: 10.1037/0096-3445.117.3.288

Arendasy, M. H.-M. (2008). Intelligence-Structure-Battery: [Intelligenz-StrukturBatterie]. Mödling: Schuhfried.

Arendasy, M. E., and Sommer, M. (2012). Using automatic item generation to meet the increasing item demands of high-stakes educational and occupational assessment. Learn. Individ. Differ. 22, 112-117. doi: 10.1016/j.lindif.2011. 11.005

Ayaz, H., Izzetoglu, M., Platek, S. M., Bunce, S., Izzetoglu, K., Pourrezaei, K., et al. (2006). "Registering fNIR data to brain surface image using MRI support previous evidence by showing that neural efficiency eases demands on EF, although it is contingent on task constraints. Our results also provide further evidence in the importance of practicing a more complex version of a task prior to executing a simpler version for learning and performance. We plan to expand our exploration of PFC activity between the two- and three-dimensional ToH conditions to children to narrow the potential points of impairment on the perception-cognitionaction continuum in certain developmental disabilities.

\section{ETHICS STATEMENT}

All subjects gave written informed consent in accordance with the Declaration of Helsinki prior to participation. The protocol was approved by the Institutional Review Board at the University of Delaware.

\section{AUTHOR CONTRIBUTIONS}

NG and KM designed the experiment. KM and EB collected the data. $\mathrm{KM}$ and $\mathrm{BB}$ analyzed the data and prepared all figures. KM, EB and NG drafted the manuscript. NG and BB provided critical revisions. All authors approved the manuscript to be published.

\section{ACKNOWLEDGMENTS}

We would like to thank Reza Koiler for his indispensable assistance in participant recruitment, data and signal processing, in addition to modeling for Figure 2. We would also like to thank Matthew Paul for developing the Tower of Hanoi computerized condition. Last, we would like to thank Dr Mary Martin for her invaluable support and advocacy in completing this project.

\section{SUPPLEMENTARY MATERIAL}

The Supplementary Material for this article can be found online at: https://www.frontiersin.org/articles/10.3389/fnhum. 2019.00156/full\#supplementary-material

templates," in Engineering in Medicine and Biology Society, 2006 EMBS'06 28th Annual International Conference of the IEEE (New York, NY: IEEE), 2671-2674.

Ayaz, H., Onaral, B., Izzetoglu, K., Shewokis, P. A., McKendrick, R., and Parasuraman, R. (2013). Continuous monitoring of brain dynamics with functional near infrared spectroscopy as a tool for neuroergonomic research: empirical examples and a technological development. Front. Hum. Neurosci. 7:871. doi: 10.3389/fnhum.2013.00871

Ayaz, H., Shewokis, P. A., Bunce, S., Izzetoglu, K., Willems, B., and Onaral, B. (2012). Optical brain monitoring for operator training and mental workload assessment. Neuroimage 59, 36-47. doi: 10.1016/j.neuroimage.2011. 06.023

Ayaz, H., Shewokis, P. A., Bunce, S. C., and Onaral, B. (2018). U.S. Patent No.9,946,344. Washington, DC: U.S. Patent and Trademark Office.

Ayaz, H., Shewokis, P. A., Curtin, A., Izzetoglu, M., Izzetoglu, K., and Onaral, B. (2011). Using MazeSuite and functional near infrared spectroscopy to study learning in spatial navigation. J. Vis. Exp. 56:3443. doi: 10 $3791 / 3443$

Baker, S. C., Rogers, R. D., Owen, A. M., Frith, C. D., Dolan, R. J., Frackowiak, R. S. J., et al. (1996). Neural systems engaged by planning: a 
PET study of the Tower of London task. Neuropsychologia 34, 515-526. doi: 10.1016/0028-3932(95)00133-6

Ball, G., Stokes, P. R., Rhodes, R. A., Bose, S. K., Rezek, I., Wink, A. M., et al. (2011). Executive functions and prefrontal cortex: a matter of persistence? Front. Syst. Neurosci. 5:3. doi: 10.3389/fnsys.2011.00003

Basso Moro, S., Cutini, S., Ursini, M. L., Ferrari, M., and Quaresima, V. (2013). Prefrontal cortex activation during story encoding/retrieval: a multi-channel functional near-infrared spectroscopy study. Front. Hum. Neurosci. 7:925. doi: 10.3389/fnhum.2013.00925

Boghi, A., Rasetti, R., Avidano, F., Manzone, C., Orsi, L., D’Agata, F., et al. (2006). The effect of gender on planning: an fMRI study using the Tower of London task. Neuroimage 33, 999-1010. doi: 10.1016/j.neuroimage.2006.07.022

Bonetti, L. V., Hassan, S. A., Lau, S. T., Melo, L. T., Tanaka, T., Patterson, K. K., et al. (2019). Oxyhemoglobin changes in the prefrontal cortex in response to cognitive tasks: a systematic review. Int. J. Neurosci. 129, 195-203. doi: 10.1080/00207454.2018.1518906

Bunce, S. C., Izzetoglu, M., Izzetoglu, K., Onaral, B., and Pourrezaei, K. (2006). Functional near-infrared spectroscopy. IEEE Eng. Med. Biol. Mag. 25, 54-62. doi: 10.1109/MEMB.2006.1657788

Caçola, P., Getchell, N., Srinivasan, D., Alexandrakis, G., and Liu, H. (2018). Cortical activity in fine-motor tasks in children with developmental coordination disorder: a preliminary fNIRS study. Int. J. Dev. Neurosci. 65, 83-90. doi: 10.1016/j.ijdevneu.2017.11.001

Campbell, Z., Zakzanis, K. K., Jovanovski, D., Joordens, S., Mraz, R., and Graham, S. J. (2009). Utilizing virtual reality to improve the ecological validity of clinical neuropsychology: an FMRI case study elucidating the neural basis of planning by comparing the Tower of London with a three-dimensional navigation task. Appl. Neuropsychol. 16, 295-306. doi: 10.1080/09084280903297891

Casey, B. J., Vauss, Y. C., Chused, A., and Swedo, S. E. (1994). Cognitive functioning in Sydenham's chorea: part 2. Executive functioning. Dev. Neuropsychol. 10, 89-96. doi: 10.1080/87565649409540570

Cope, M., and Delpy, D. T. (1988). System for long-term measurement of cerebral blood and tissue oxygenation on newborn infants by near infra-red transillumination. Med. Biol. Eng. Comput. 26, 289-294. doi: $10.1007 /$ bf02447083

Crescentini, C., Seyed-Allaei, S., Vallesi, A., and Shallice, T. (2012). Two networks involved in producing and realizing plans. Neuropsychologia 50, 1521-1535. doi: 10.1016/j.neuropsychologia.2012.03.005

den Braber, A., van't Ent, D., Blokland, G. A., van Grootheest, D. S., Cath, D. C., Veltman, D. J., et al. (2008). An fMRI study in monozygotic twins discordant for obsessive-compulsive symptoms. Biol. Psychol. 79, 91-102. doi: 10.1016/j. biopsycho.2008.01.010

de Ruiter, M. B., Reneman, L., Boogerd, W., Veltman, D. J., van Dam, F. S., Nederveen, A. J., et al. (2009). Cerebral hyporesponsiveness and cognitive impairment ten years after chemotherapy for breast cancer. Neuroimage 47:S46. doi: 10.1016/s1053-8119(09)70066-7

Devine, S., Welsh, M. C., Retzlaff, P., Yoh, M., and Adams, C. (2001). Explicit and implicit cognitive processes underkying Tower of Hanoi performance. J. Int. Neuropsychol. Soc. 7, 250.

Dunst, B., Benedek, M., Jauk, E., Bergner, S., Koschutnig, K., Sommer, M., et al. (2014). Neural efficiency as a function of task demands. Intelligence 42, 22-30. doi: 10.1016/j.intell.2013.09.005

Ferrari, M., and Quaresima, V. (2012). A brief review on the history of human functional near-infrared spectroscopy (fNIRS) development and fields of application. Neuroimage 63, 921-935. doi: 10.1016/j.neuroimage.2012.03.049

Fishburn, F. A., Norr, M. E., Medvedev, A. V., and Vaidya, C. J. (2014). Sensitivity of fNIRS to cognitive state and load. Front. Hum. Neurosci. 8:76. doi: 10.3389/fnhum.2014.00076

Fitzgerald, P. B., Srithiran, A., Benitez, J., Daskalakis, Z. Z., Oxley, T. J., Kulkarni, J., et al. (2008). An fMRI study of prefrontal brain activation during multiple tasks in patients with major depressive disorder. Hum. Brain Mapp. 29, 490-501. doi: $10.1002 / \mathrm{hbm} .20414$

Goel, V., and Grafman, J. (1995). Are the frontal lobes implicated in "planning" functions? Interpreting data from the Tower of Hanoi. Neuropsychologia 33, 623-642. doi: 10.1016/0028-3932(95)90866-p

Griebling, J., Minshew, N. J., Bodner, K., Libove, R., Bansal, R., Konasale, P., et al. (2010). Dorsolateral prefrontal cortex magnetic resonance imaging measurements and cognitive performance in autism. J. Child Neurol. 25, 856-863. doi: 10.1177/0883073809351313

Guevara, M. Á., González, M. H., Martínez, L. E. R., and Aguirre, F. A. R. (2013). Performance of the towers of Hanoi task and cortical electroencephalographic power changes associated with infancy, adolescence and early adulthood. Exp. Brain Res. 231, 315-324. doi: 10.1007/s00221-013-3693-z

Gulliksen, H. (2013). Theory of Mental Tests. New York, NY: Routledge.

Haahr, M. (1998). True Random Service. Available online at: https://www.random. org/integers/. Accessed August 30, 2018.

Hahn, A., Wadsak, W., Windischberger, C., Baldinger, P., Höflich, A. S., Losak, J., et al. (2012). Differential modulation of the default mode network via serotonin-1A receptors. Proc. Natl. Acad. Sci. U S A 109, 2619-2624. doi: 10.1073/pnas.1117104109

Haier, R. J., Siegel, B. V. Jr., MacLachlan, A., Soderling, E., Lottenberg, S., and Buchsbaum, M. S. (1992). Regional glucose metabolic changes after learning a complex visuospatial/motor task: a positron emission tomographic study. Brain Res. 570, 134-143. doi: 10.1016/0006-8993(92)90573-r

Haier, R. J., Siegel, B. V. Jr., Nuechterlein, K. H., Hazlett, E., Wu, J. C., Paek, J., et al. (1988). Cortical glucose metabolic rate correlates of abstract reasoning and attention studied with positron emission tomography. Intelligence 12, 199-217. doi: 10.1016/0160-2896(88)90016-5

Haig, A. R., Gordon, E., and Hook, S. (1997). To scale or not to scale: McCarthy and Wood revisited. Electroencephalogr. Clin. Neurophysiol. 103, 323-325. doi: 10.1016/s0013-4694(97)00009-6

Halgren, E., Boujon, C., Clarke, J., Wang, C., and Chauvel, P. (2002). Rapid distributed fronto-parieto-occipital processing stages during working memory in humans. Cereb. Cortex 12, 710-728. doi: 10.1093/cercor/12.7.710

Head, D., Raz, N., Gunning-Dixon, F., Williamson, A., and Acker, J. D. (2002). Age-related differences in the course of cognitive skill acquisition: the role of regional cortical shrinkage and cognitive resources. Psychol. Aging 17, 72-84. doi: 10.1037/0882-7974.17.1.72

Homan, R. W., Herman, J., and Purdy, P. (1987). Cerebral location of international 10-20 system electrode placement. Electroencephalogr. Clin. Neurophysiol. 66, 376-382. doi: 10.1016/0013-4694(87)90206-9

Honey, G. D., Fu, C. H. Y., Kim, J., Brammer, M. J., Croudace, T. J., Suckling, J., et al. (2002). Effects of verbal working memory load on corticocortical connectivity modeled by path analysis of functional magnetic resonance imaging data. Neuroimage 17, 573-582. doi: 10.1016/s1053-8119(02) 91193-6

Hoshi, Y. (2007). Functional near-infrared spectroscopy: current status and future prospects. J. Biomed. Opt. 12:062106. doi: 10.1117/1.2804911

Huhn, A. S., Sweeney, M. M., Brooner, R. K., Kidorf, M. S., Tompkins, D. A., Ayaz, H., et al. (2019). Prefrontal cortex response to drug cues, craving and current depressive symptoms are associated with treatment outcomes in methadone-maintained patients. Neuropsychopharmacology 44, 826-833. doi: 10.1038/s41386-018-0252-0

Irani, F., Platek, S. M., Bunce, S., Ruocco, A. C., and Chute, D. (2007). Functional near infrared spectroscopy (fNIRS): an emerging neuroimaging technology with important applications for the study of brain disorders. Clin. Neuropsychol. 21, 9-37. doi: 10.1080/13854040600910018

Izzetoglu, M., Izzetoglu, K., Bunce, S., Ayaz, H., Devaraj, A., Onaral, B., et al. (2005). Functional near-infrared neuroimaging. IEEE Trans. Neural Syst. Rehabil. Eng. 13, 153-159. doi: 10.1109/TNSRE.2005.847377

Just, M. A., Cherkassky, V. L., Keller, T. A., Kana, R. K., and Minshew, N. J. (2007). Functional and anatomical cortical underconnectivity in autism: evidence from an FMRI study of an executive function task and corpus callosum morphometry. Cereb. Cortex 17, 951-961. doi: 10.1093/cercor/bhl006

Kaller, C. P., Rahm, B., Spreer, J., Weiller, C., and Unterrainer, J. M. (2011). Dissociable contributions of left and right dorsolateral prefrontal cortex in planning. Cereb. Cortex 21, 307-317. doi: 10.1093/cercor/bhq096

Kalyuga, S., Chandler, P., and Sweller, J. (2004). When redundant on-screen text in multimedia technical instruction can interfere with learning. Hum. Factors 46, 567-581. doi: 10.1518/hfes.46.3.567.1640

Kantak, S. S., Zahedi, N., and McGrath, R. (2017). Complex skill training transfers to improved performance and control of simpler tasks after stroke. Phys. Ther. 97, 718-728. doi: 10.1093/ptj/pzx042

Kawato, M. (1999). Internal models for motor control and trajectory planning. Curr. Opin. Neurobiol. 9, 718-727. doi: 10.1016/s0959-4388(99)00028-8 
Kim, H. Y., Seo, K., Jeon, H. J., Lee, U., and Lee, H. (2017). Application of functional near-infrared spectroscopy to the study of brain function in humans and animal models. Mol. Cells 40, 523-532. doi: 10.14348/molcells. 2017.0153

Kleinschmidt, A., Obrig, H., Requardt, M., Merboldt, K. D., Dirnagl, U., Villringer, A., et al. (1996). Simultaneous recording of cerebral blood oxygenation changes during human brain activation by magnetic resonance imaging and near-infrared spectroscopy. J. Cereb. Blood Flow Metab. 16, 817-826. doi: 10.1097/00004647-199609000-00006

Koch, J. K. L., Miguel, H., and Smiley-Oyen, A. L. (2018). Prefrontal activation during Stroop and Wisconsin card sort tasks in children with developmental coordination disorder: a NIRS study. Exp. Brain Res. 236, 3053-3064. doi: 10.1007/s00221-018-5358-4

Kuhtz-Buschbeck, J. P., Mahnkopf, C., Holzknecht, C., Siebner, H., Ulmer, S., and Jansen, O. (2003). Effector-independent representations of simple and complex imagined finger movements: a combined fMRI and TMS study. Eur. J. Neurosci. 18, 3375-3387. doi: 10.1111/j.1460-9568.2003.03066.x

Lamm, C., Bauer, H., Vitouch, O., Durec, S., Gronister, R., and Gstättner, R. (2001). Restriction of task processing time affects cortical activity during processing of a cognitive task: an event-related slow cortical potential study. Cogn. Brain Res. 10, 275-282. doi: 10.1016/s0926-6410(00)00048-3

Lee, T. D., Wulf, G., and Schmidt, R. A. (1992). Contextual interference in motor learning: dissociated effects due to the nature of task variations. Q. J. Exp. Psychol. 44, 627-644. doi: 10.1080/14640749208401303

Lefebvre, S., Dricot, L., Laloux, P., Gradkowski, W., Desfontaines, P., Evrard, F., et al. (2015). Neural substrates underlying motor skill learning in chronic hemiparetic stroke patients. Front. Hum. Neurosci. 9:320. doi: 10.3389/fnhum. 2015.00320

Liang, L. Y., Chen, J. J. J., Shewokis, P. A., and Getchell, N. (2016a). Developmental and condition-related changes in the prefrontal cortex activity during rest. J. Behav. Brain Sci. 6, 485-497. doi: 10.4236/jbbs.2016.612044

Liang, L. Y., Shewokis, P. A., and Getchell, N. (2016b). Brain activation in the prefrontal cortex during motor and cognitive tasks in adults. J. Behav. Brain Sci. 6, 463-474. doi: 10.4236/jbbs.2016.612042

Lock, C., Welsh, M. C., Adams, C., and Kurtz, A. (2002). Tower of Hanoi: influence of strategy instruction and extended practice on performance. J. Int. Neuropsychol. Soc. 8, 229.

McCarthy, G., and Wood, C. C. (1985). Scalp distributions of event-related potentials: an ambiguity associated with analysis of variance models. Electroencephalogr. Clin. Neurophysiol. 62, 203-208. doi: 10.1016/01685597(85)90015-2

Meehan, S. K., Randhawa, B., Wessel, B., and Boyd, L. A. (2011). Implicit sequencespecific motor learning after subcortical stroke is associated with increased prefrontal brain activations: an fMRI Study. Hum. Brain Mapp. 32, 290-303. doi: $10.1002 / \mathrm{hbm} .21019$

Miyake, A., and Friedman, N. P. (2012). The nature and organization of individual differences in executive functions: four general conclusions. Curr. Dir. Psychol. Sci. 21, 8-14. doi: 10.1177/0963721411429458

Miyake, A., Friedman, N. P., Emerson, M. J., Witzki, A. H., Howerter, A., and Wager, T. D. (2000). The unity and diversity of executive functions and their contributions to complex "frontal lobe" tasks: a latent variable analysis. Cogn. Psychol. 41, 49-100. doi: 10.1006/cogp.1999.0734

Moriguchi, Y., and Hiraki, K. (2013). Prefrontal cortex and executive function in young children: a review of NIRS studies. Front. Hum. Neurosci. 7:867. doi: 10.3389/fnhum.2013.00867

Mushiake, H., Sakamoto, K., Saito, N., Inui, T., Aihara, K., and Tanji, J. (2009). Involvement of the prefrontal cortex in problem solving. Int. Rev. Neurobiol. 85, 1-11. doi: 10.1016/S0074-7742(09)85001-0

Neubauer, A. C., and Fink, A. (2009). Intelligence and neural efficiency. Neurosci. Biobehav. Rev. 33, 1004-1023. doi: 10.1016/j.neubiorev.2009.04.001

Nudo, R. J., Wise, B. M., SiFuentes, F., and Milliken, G. W. (1996). Neural substrates for the effects of rehabilitative training on motor recovery after ischemic infarct. Science 272, 1791-1794. doi: 10.1126/science.272.5269.1791

Oldfield, R. C. (1971). The assessment and analysis of handedness: the Edinburgh inventory. Neuropsychologia 9, 97-113. doi: 10.1016/0028-3932(71)90067-4

Öngür, D., and Price, J. L. (2000). The organization of networks within the orbital and medial prefrontal cortex of rats, monkeys and humans. Cereb. Cortex 10, 206-219. doi: 10.1093/cercor/10.3.206
Osaka, N., Osaka, M., Kondo, H., Morishita, M., Fukuyama, H., and Shibasaki, H. (2004). The neural basis of executive function in working memory: an fMRI study based on individual differences. Neuroimage 21, 623-631. doi: 10.1016/j. neuroimage.2003.09.069

Owen, A. M., McMillan, K. M., Laird, A. R., and Bullmore, E. (2005). Nback working memory paradigm: a meta-analysis of normative functional neuroimaging studies. Hum. Brain Mapp. 25, 46-59. doi: 10.1002/hbm.20131

Paas, F., Tuovinen, J. E., Tabbers, H., and Van Gerven, P. W. (2003). Cognitive load measurement as a means to advance cognitive load theory. Educ. Psychol. 38, 63-71. doi: 10.1207/s15326985ep3801_8

Paas, F. G., and Van Merriënboer, J. J. (1993). The efficiency of instructional conditions: an approach to combine mental effort and performance measures. Hum. Factors 35, 737-743. doi: 10.1177/001872089303500412

Periáñez, J. A., Maestú, F., Barceló, F., Fernández, A., Amo, C., and Alonso, T. O. (2004). Spatiotemporal brain dynamics during preparatory set shifting: MEG evidence. Neuroimage 21, 687-695. doi: 10.1016/j.neuroimage.2003. 10.008

Plautz, E. J., Milliken, G. W., and Nudo, R. J. (2000). Effects of repetitive motor training on movement representations in adult squirrel monkeys: role of use versus learning. Neurobiol. Learn. Mem. 74, 27-55. doi: 10.1006/nlme. 1999.3934

Porebski, O. (1954). A psychological and statistical study of speed and power as variables of human ability. Occup. Psychol. 28, 218-231.

Ruiz-Díaz, M., Hernández-González, M., Guevara, M. A., Amezcua, C., and Ågmo, A. (2012). Prefrontal EEG correlation during tower of hanoi and WCST performance: effect of emotional visual stimuli. J. Sex. Med. 9, 2631-2640. doi: 10.1111/j.1743-6109.2012.02782.x

Ruocco, A. C., Rodrigo, A. H., Lam, J., Di Domenico, S., Graves, B., and Ayaz, H. (2014). A problem-solving task specialized for functional neuroimaging: validation of the Scarborough adaptation of the Tower of London (S-TOL) using near-infrared spectroscopy. Front. Hum. Neurosci. 8:185. doi: $10.3389 /$ fnhum. 2014.00185

Saint-Cyr, J. A., Taylor, A. E., and Lang, A. E. (1988). Procedural learning and neostyrial dysfunction in man. Brain 111, 941-960. doi: 10.1093/brain/ 111.4.941

Salesforce Company. (2018). Heroku Development Center. Available online at: https://devcenter.heroku.com/articles/heroku-dashboard. Accessed May 9, 2018.

Schall, U., Johnston, P., Lagopoulos, J., Jüptner, M., Jentzen, W., Thienel, R., et al. (2003). Functional brain maps of Tower of London performance: a positron emission tomography and functional magnetic resonance imaging study. Neuroimage 20, 1154-1161. doi: 10.1016/s1053-8119(03)00338-0

Selemon, L. D., and Goldman-Rakic, P. S. (1988). Common cortical and subcortical targets of the dorsolateral prefrontal and posterior parietal cortices in the rhesus monkey: evidence for a distributed neural network subserving spatially guided behavior. J. Neurosci. 8, 4049-4068. doi: 10.1523/jneurosci.0811-04049.1988

Shuai, L., Daley, D., Wang, Y. F., Zhang, J. S., Kong, Y. T., Tan, X., et al. (2017). Executive function training for children with attention deficit hyperactivity disorder. Chin. Med. J. 130, 549-558. doi: 10.4103/0366-6999.200541

Simmonds, D. J., Pekar, J. J., and Mostofsky, S. H. (2008). Meta-analysis of Go/No-go tasks demonstrating that fMRI activation associated with response inhibition is task-dependent. Neuropsychologia 46, 224-232. doi: 10.1016/j. neuropsychologia.2007.07.015

Simon, H. A. (1975). The functional equivalence of problem solving skills. Cogn. Psychol. 7, 268-288. doi: 10.1016/0010-0285(75)90012-2

Slomine, B. S., Gerring, J. P., Grados, M. A., Vasa, R., Brady, K. D., Christensen, J. R., et al. (2002). Performance on measures of executive function following pediatric traumatic brain injury. Brain Inj. 16, 759-772. doi: 10.1080/02699050210127286

Smith, L. L., Banich, M. T., and Friedman, N. P. (2019). Individual differences in mixing costs relate to general executive functioning. J. Exp. Psychol. Learn. Mem. Cogn. 45, 606-613. doi: 10.1037/xlm0000613

Smith, A. B., Taylor, E., Brammer, M., Toone, B., and Rubia, K. (2006). Task-specific hypoactivation in prefrontal and temporoparietal brain regions during motor inhibition and task switching in medication-naive children and adolescents with attention deficit hyperactivity disorder. Am. J. Psychiatry 163, 1044-1051. doi: 10.1176/appi.ajp.163.6.1044 
Stokes, P. R., Rhodes, R. A., Grasby, P. M., and Mehta, M. A. (2011). The effects of the COMT val 108/158 met polymorphism on BOLD activation during working memory, planning and response inhibition: a role for the posterior cingulate cortex? Neuropsychopharmacology 36, 763-771. doi: 10.1038/npp. 2010.210

Strangman, G., Culver, J. P., Thompson, J. H., and Boas, D. A. (2002). A quantitative comparison of simultaneous BOLD fMRI and NIRS recordings during functional brain activation. Neuroimage 17, 719-731. doi: 10.1016/s1053-8119(02)91227-9

Stuss, D. B. (1986). The Frontal Lobes. New York, NY: Raven Press.

Sweller, J. (2008). "Human cognitive architecture." in Handbook of Research on Educational Communications and Technology, 3rd Edn., eds J. Spector, M. Merrill, J. Van Merrienboer and M. Driscoll (NY: Erlbaum), 369-381.

Tak, S., Uga, M., Flandin, G., Dan, I., and Penny, W. D. (2016). Sensor space group analysis for fNIRS data. J. Neurosci. Methods 264, 103-112. doi: 10.1016/j. jneumeth.2016.03.003

Taylor, C. (2013). Cognitive load theory-sometimes less is more. J. Sch. Educ. Technol. 9, 61-68. doi: 10.26634/jsch.9.1.2402

Unni, A., Ihme, K., Surm, H., Weber, L., Lüdtke, A., Nicklas, D., et al. (2015). "Brain activity measured with fNIRS for the prediction of cognitive workload," in Cognitive Infocommunications (CogInfoCom), 2015 6th IEEE International Conference (Gyor: IEEE), 349-354.

Van Breukelen, G. J., and Roskam, E. E. C. I. (1991). "A Rasch model for the speed-accuracy tradeoff in time limited tests," in Mathematical Psychology, eds J.-P. Doignon and J.-C. Falmagnecs (New York, NY: Springer), 251-271.

Wadden, K. P., Woodward, T. S., Metzak, P. D., Lavigne, K. M., Lakhani, B., Auriat, A. M., et al. (2015). Compensatory motor network connectivity is associated with motor sequence learning after subcortical stroke. Behav. Brain Res. 286, 136-145. doi: 10.1016/j.bbr.2015.02.054

Wagner, G., Koch, K., Reichenbach, J. R., Sauer, H., and Schlösser, R. G. (2006). The special involvement of the rostrolateral prefrontal cortex in planning abilities: an event-related fMRI study with the Tower of London paradigm. Neuropsychologia 44, 2337-2347. doi: 10.1016/j.neuropsychologia.2006.05.014

Welsh, M. C., and Huizinga, M. (2001). The development and preliminary validation of the Tower of Hanoi-Revised. Assessment 8, 167-176. doi: 10.1177/107319110100800205

Welsh, M. C., and Huizinga, M. (2005). Tower of Hanoi disk-transfer task: influences of strategy knowledge and learning on performance. Learn. Individ. Differ. 15, 283-298. doi: 10.1016/j.lindif.2005.05.002

Welsh, M. C., Satterlee-Cartmell, T., and Stine, M. (1999). Towers of Hanoi and London: contribution of working memory and inhibition to performance. Brain Cogn. 41, 231-242. doi: 10.1006/brcg.1999.1123
Wong, A. L., Haith, A. M., and Krakauer, J. W. (2015). Motor planning. Neuroscientist 21, 385-398. doi: 10.1177/1073858414541484

Wood, J. N., and Grafman, J. (2003). Human prefrontal cortex: processing and representational perspectives. Nat. Rev. Neurosci. 4, 139-147. doi: $10.1038 / \mathrm{nrn} 1033$

Yang, Y., and Raine, A. (2009). Prefrontal structural and functional brain imaging findings in antisocial, violent, and psychopathic individuals: a meta-analysis. Psychiatry Res. 174, 81-88. doi: 10.1016/j.pscychresns.2009. 03.012

Yin, X., Xu, B., Jiang, C., Fu, Y., Wang, Z., Li, H., et al. (2015). A hybrid BCI based on EEG and ANIRS signals improves the performance of decoding motor imagery of both force and speed of hand clenching. J. Neural Eng. 12:036004. doi: 10.1088/1741-2560/12/3/036004

Yu, Y., Zhao, Y., Si, Y., Ren, Q., Ren, W., Jing, C., et al. (2016). Estimation of the cool executive function using frontal electroencephalogram signals in first-episode schizophrenia patients. Biomed. Eng. Online 15:131. doi: 10.1186/s12938-016-0282-y

Zhang, H., Duan, L., Zhang, Y. J., Lu, C. M., Liu, H., and Zhu, C. Z. (2011). Test-retest assessment of independent component analysis-derived resting-state functional connectivity based on functional near-infrared spectroscopy. Neuroimage 55, 607-615. doi: 10.1016/j.neuroimage.2010. 12.007

Zhang, H., Zhang, Y. J., Lu, C. M., Ma, S. Y., Zang, Y. F., and Zhu, C. Z. (2010). Functional connectivity as revealed by independent component analysis of resting-state fNIRS measurements. Neuroimage 51, 1150-1161. doi: 10.1016/j. neuroimage.2010.02.080

Zhu, Y., Liu, X., Wang, H., Jiang, T., Fang, Y., Hu, H., et al. (2010). Reduced prefrontal activation during Tower of London in first-episode schizophrenia: a multi-channel near-infrared spectroscopy study. Neurosci. Lett. 478, 136-140. doi: 10.1016/j.neulet.2010.05.003

Conflict of Interest Statement: The authors declare that the research was conducted in the absence of any commercial or financial relationships that could be construed as a potential conflict of interest.

Copyright (C) 2019 Milla, Bakhshipour, Bodt and Getchell. This is an open-access article distributed under the terms of the Creative Commons Attribution License (CC BY). The use, distribution or reproduction in other forums is permitted, provided the original author(s) and the copyright owner(s) are credited and that the original publication in this journal is cited, in accordance with accepted academic practice. No use, distribution or reproduction is permitted which does not comply with these terms. 